\title{
Cable bracing design in adaptable dual control systems
}

\author{
M. C. Phocas \& T. L. Sophocleous \\ Department of Architecture, University of Cyprus, Nicosia, Cyprus
}

\begin{abstract}
Structural control through energy dissipation systems has been increasingly implemented internationally in the last years and has proven to be a most promising strategy for earthquake safety of structures. The present paper examines an alternative control system development for achieving dynamic structural adaptability. The prototype control system consists of a hysteretic energy dissipation device of triangular steel plates and a tension-only bracing with closed circuit realized through implementation of rotating discs at the braces connections. A typical configuration design of the kinetic mechanism consists of a portal- and a chevron cable bracing. Based on three representative international strong earthquake motions of differing frequency contents, parametric dynamic analyses of the SDOF system responses mainly characterized by high energy dissipation have been performed by the authors in previous studies with regard to the mechanical characteristics of the hysteretic damper, i.e. elastic stiffness and yield force, whereas the cables were modelled as frame objects with zero compression limit. In the present study the optimum controlled system is further investigated in its earthquake responses with different cable stiffness values and a pretension stress. The respective numerical nonlinear analyses conducted exemplify the earthquake performance of the bracing-damper mechanism, while a linear elastic resistance of the tension-only members is verified.

Keywords: earthquake resistance, frame structures, passive control, cable design.
\end{abstract}




\section{Introduction}

An essentially linear elastic behaviour of frame structures subjected to earthquake actions may be achieved through integration of damping devices, such as passive metallic yielding-, friction-, viscoelastic- and viscous damping devices [1-3]. In principle the damping devices are attached on steel bracings that may be of accountable self-weight and stiffness. The bracing members are stressed in compression, tension and bending, and increase the overall stiffness of the system $[4,5]$. In addition, their seismic control resistance weakens by the fact that under cyclic loading in every half-loading cycle the compression diagonal buckles and cannot participate in the energy dissipation process.

The implementation of tension-only bracings with damping devices in frame structures may be realized through the development of suitable bracing-damper configurations, whereas all bracing members contribute to the operation of the integrated damper during the entire load duration. An optimization of the control system's seismic response may thus be achieved. This concept was initially followed by Filiautrault and Cherry [6] with the Pall-Marsh friction mechanism using slender cross braces. Recently proposed control systems that consist of hysteretic dampers and slender bracing members are based in their operation on relative displacements between the tension members. Hysteresis is achieved through optimization of the integrated hysteretic dampers plates' section $[7,8]$.

Related studies on the development of a tension-only bracing-damper mechanism in different bracings configurations have been conducted in $[9,10]$. The Adaptable Dual Control Structures, ADCS, developed consist of a cable bracing with closed circuit and a hysteretic damper of steel plates. The hysteretic dampers consist of $\mathrm{X}$ - or triangular-shaped steel plates for achieving uniform deformation curvatures over the sections' height, as applied in the examples of ADAS- and TADAS-devices [11-13]. During strong ground motions relative displacements between the bracing and the frame member force the interconnected hysteretic damper to yield in its plastic region and dissipate energy. ADCS is only responsible for the earthquake forces and enables in all cases the elastic response of the primary system.

Based on three international strong ground motions with different frequency contents, ADCS effective response behaviour with regard to energy dissipation maximization, without increase of the system's maximum base shear and relative displacements have been verified in [14]. In the studies conducted the cables had a constant diameter and were modelled as frame objects with zero compression limit. In the present study an ADCS-configuration of a portal- and a chevron bracing, ADCS2, assigned with the selected mechanical characteristics of the hysteretic damper, i.e. elastic stiffness and yield force, in [14] is further investigated in its earthquake responses with different cable stiffness values and a constant pretension stress. Respective numerical nonlinear analyses conducted exemplify the earthquake performance of the bracing-damper mechanism, while ensuring a linear elastic resistance of the tension-only members. 


\section{Optimum design configuration}

ADCS are based on a dual function of the component members, resulting in two practically uncoupled systems. The primary frame is responsible for the static vertical and horizontal forces, while the bracing-damper mechanism, for the earthquake forces and the necessary energy dissipation. Inelastic deformations are only developed in the hysteretic damper.

A particular ADCS-configuration of a portal- and a chevron bracing, ADCS2, is investigated in the present paper. All cables of the proposed control system are fixed connected at the bottom of the columns and are free to move horizontally at the connecting joints of the frame, fig. 1(a). A hysteretic damper is placed between the beam and the horizontal member of the portal cables. An additional pair of chevron braces is connected to a middle eccentric disc fixed at the lower horizontal connecting plate of the damper. The hysteretic damper consists of a series of triangular shaped steel plates, welded on two horizontal plates. The plates' characteristic shape enables uniform deformation curvatures over the sections' height.

The kinetic mechanism of ADCS2 is activated during the dynamic excitation by the horizontally induced motion at the base of the structure. In every halfloading cycle the respective displacement of the primary frame is followed by the cables through rotations of the eccentric discs at the braces connections. The rotations result to respective axial displacements of the connection joints to the cables, stretching the members. Since the bracing members form two independent kinetically closed polygon circuits, ideally the reactions on the primary frame are neutralized and the members remain under tension, fig. 1(b). The portal bracing is primarily responsible for the relative displacements of the bracing to the primary system leading to deformations of the interconnected hysteretic damper, whereas the chevron bracing is responsible through its recentering action, not only for further increase of the damper's deformations and the resulting energy dissipation, but also for decrease of the sensitivity of the control mechanism to the earthquake loading.

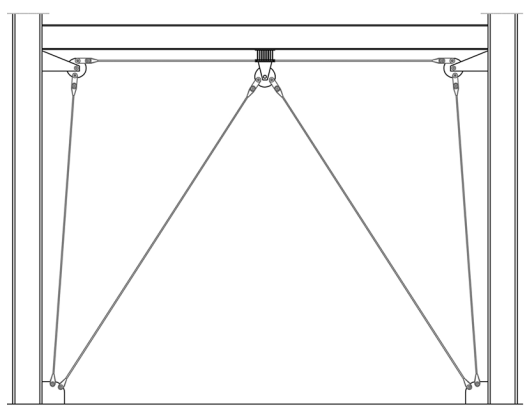

(a)

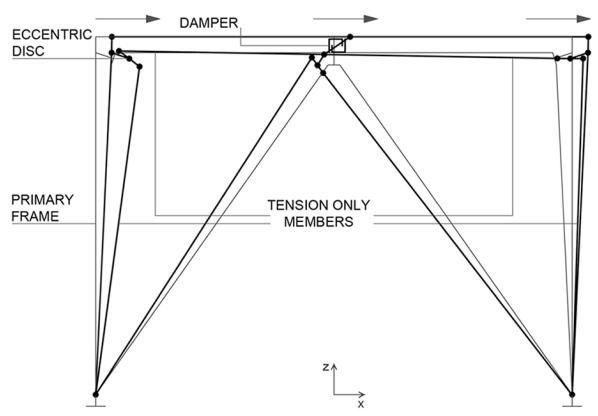

(b)

Figure 1: Adaptable Dual Control System with bracing-damper mechanism: (a) System configuration; (b) Kinetic system's model. 


\section{Model for dynamic analysis}

The primary frame with $6.0 \mathrm{~m}$ length and $4.5 \mathrm{~m}$ height was modeled with the Finite-Element software program SAP2000, having considered associated restraints for the columns axial deformations and relative out of plane rotations. The structure was dimensioned to resist a vertical load of $\mathrm{G}=1200 \mathrm{kN}$, a horizontal wind load of $\mathrm{W}=15 \mathrm{kN}$ and a minimum of $25 \%$ of the static equivalent seismic loads. IPBL550 and IPBv500 sections were selected according to Eurocode 3 for the beam and columns respectively (S235, E= $2.1 \times 10^{4} \mathrm{kN} / \mathrm{cm}^{2}, \rho=78.5 \mathrm{kN} / \mathrm{m}^{3}$ ). The primary frames fundamental period results to $\mathrm{T}=0.34 \mathrm{~s}$ and its stiffness to $\mathrm{k}=41717.37 \mathrm{kN} / \mathrm{m}$. Furthermore $0 \%$ damping was assumed for the dynamic loading.

The design of the bracing-damper mechanism is based on the selection of the dampers stiffness, $\mathrm{k}_{\mathrm{d}}$ and yield force, $\mathrm{P}_{\mathrm{y}}$, so that maximum hysteresis is achieved [14]. In addition the maximum base shear and the relative displacements of the controlled system hold in bounds with the respective responses of the primary system. Based on three representative international strong earthquake motions of differing frequency contents presented in table 1, numerical analyses previously conducted by the authors for a cables constant diameter of $\mathrm{C}_{\mathrm{Fd}}=20 \mathrm{~mm}$ $\left(E=1.6 \times 10^{4} \mathrm{kN} / \mathrm{cm}^{2}, \mathrm{k}_{\mathrm{b}}=2895.34 \mathrm{kN} / \mathrm{m}, \mathrm{f}_{\mathrm{e}}=140 \mathrm{kN} / \mathrm{cm}^{2}\right)$ concluded to the selection of a hysteretic damper realized with 6 plates of $1.6 \mathrm{~cm}$ thickness, $35 \mathrm{~cm}$ height and $5 \mathrm{~cm}$ width each, i.e. ADCS2 with damper: 616355 (S235, E= $1.6 \times 10^{4} \mathrm{kN} / \mathrm{cm}^{2}, \mathrm{f}_{\mathrm{y}}=24 \mathrm{kN} / \mathrm{cm}^{2}, \rho=78.5 \mathrm{kN} / \mathrm{m}^{3}$ ) [14]. The respective optimum DR value that involves the ratio of the dampers stiffness, $\mathrm{k}_{\mathrm{d}}$, to the yield force, $\mathrm{P}_{\mathrm{y}}$, amounts to $114.31 / \mathrm{m}$, with $\mathrm{k}_{\mathrm{d}}=1003.10 \mathrm{kN} / \mathrm{m}, \mathrm{k}^{\prime}=\mathrm{k}_{\mathrm{d}} / \mathrm{k}=0.024$, $\mathrm{k}^{\prime \prime}=\mathrm{k}_{\mathrm{b}} / \mathrm{k}_{\mathrm{d}}=2.89, \mathrm{P}_{\mathrm{y}}=8.78 \mathrm{kN}$. In the numerical analyses the cables were modelled as frame objects with zero compression limit and no prestress. The hysteretic damper that exhibits a nonlinear behaviour was modelled with a link element, assigned to follow the uniaxial plasticity Wen model of hysteresis for the degree of freedom that corresponds to shear deformation [14].

Table 1: International earthquake input records.

\begin{tabular}{|c|l|c|c|c|c|}
\hline Case & \multicolumn{1}{|c|}{ Record } & Station & Mw & PGA [g] & $\begin{array}{c}\text { Duration } \\
{[\mathrm{s}]}\end{array}$ \\
\hline A & El Centro 1940 & Imperial valley, component 180 & 6.9 & 0.348 & 53.76 \\
\hline B & Kobe 1995 & JMA, component 0 & 6.9 & 0.810 & 48.00 \\
\hline C & Northridge 1994 & Olive view, component 90 & 6.7 & 0.604 & 30.00 \\
\hline
\end{tabular}

In the current study the bracing was modeled with cable elements. The simulation captures the behaviour of the slender cables and includes in the members' response formulations both, tension-stiffening and large deflections nonlinearity. The nonlinear analysis conducted makes use of the cable elements and the members' stiffness at the end of the nonlinear prestress load case. The respective prestress load case and each seismic loading case were considered 
individually by using an envelope combination for the analysis. Therefore the systems dynamic behaviour is investigated by using nonlinear modal timehistory load cases for each of the three seismic records and Ritz vector-modes from the modal load case type that considers the respective acceleration values and all elements loads. The cable stiffness is varied between five assigned values for the tension-only members' diameter, $\mathrm{C}_{\mathrm{d}}=15,20,25,30$ and $35 \mathrm{~mm}$. The way that the cables design parameters, i.e. tension and sag, interact with the seismic loads was initially traced by using the undeformed cables length (e.g. the cables length is assumed to be equal to the chord length between the undeformed positions of the two end joints), in order to determine the shape of the bracing. ADCS2- $\mathrm{C}_{\mathrm{d}}$ sensitivity analysis resulted to the selection of a suitable prestress load of $150 \mathrm{kN}$ initially applied to all bracing members and kept constant throughout the loading. For further comparison, in ADCS2- $\mathrm{C}_{\mathrm{Fd}}$ the bracing with $20 \mathrm{~mm}$ cable diameter is modelled with frame objects of zero compression limit and a target force of $109.90 \mathrm{kN}$ corresponding to a prestress of $25 \%$ of the maximum allowable stress of $\mathrm{f}_{\mathrm{e}}=140 \mathrm{kN} / \mathrm{cm}^{2}$. While ADCS2- $\mathrm{C}_{\mathrm{Fd}}$ fundamental period amounts to $\mathrm{T}=0.27 \mathrm{~s}, \mathrm{ADCS} 2-\mathrm{C}_{\mathrm{d}}$ develop a fundamental period in the range of $\mathrm{T}=0.40-0.42 \mathrm{~s}$ depending on the cables' diameter.

\section{Earthquake response behaviour}

The maximum earthquake responses of the primary frame and the controlled system assigned with the optimum damper characteristics are included in table 2 in absolute values.

Table 2: $\quad$ ADCS2 earthquake response behavior.

\begin{tabular}{|c|c|c|c|c|c|c|c|c|}
\hline Response & $\begin{array}{c}\text { Seismic } \\
\text { Case }\end{array}$ & $\begin{array}{l}\text { Primary } \\
\text { Frame }\end{array}$ & $\begin{array}{c}\mathrm{ADCS} 2- \\
\mathrm{C}_{\mathrm{Fd}}=20 \\
\mathrm{~mm}\end{array}$ & $\begin{array}{c}\mathrm{ADCS} 2- \\
\mathrm{C}_{\mathrm{d}}=15 \\
\mathrm{~mm}\end{array}$ & $\begin{array}{c}\mathrm{ADCS} 2- \\
\mathrm{C}_{\mathrm{d}}=20 \\
\mathrm{~mm}\end{array}$ & $\begin{array}{c}\mathrm{ADCS} 2- \\
\mathrm{C}_{\mathrm{d}}=25 \\
\mathrm{~mm}\end{array}$ & $\begin{array}{c}\mathrm{ADCS} 2- \\
\mathrm{C}_{\mathrm{d}}=30 \\
\mathrm{~mm}\end{array}$ & $\begin{array}{c}\mathrm{ADCS} 2- \\
\mathrm{C}_{\mathrm{d}}=35 \\
\mathrm{~mm}\end{array}$ \\
\hline \multirow{3}{*}{$\begin{array}{c}\text { EEDI } \\
{[\%]}\end{array}$} & A & - & 86 & 26 & 72 & 84 & 85 & 98 \\
\hline & $\mathrm{B}$ & - & 82 & 12 & 38 & 68 & 87 & 92 \\
\hline & $\mathrm{C}$ & - & 85 & 44 & 70 & 64 & 80 & 86 \\
\hline \multirow{3}{*}{$\begin{array}{c}\mathrm{BS}_{\max } \\
{[\mathrm{kN}]}\end{array}$} & $\mathrm{A}$ & 2102 & 1932 & 1309 & 1507 & 2433 & 2190 & 1334 \\
\hline & B & 5570 & 4830 & 11648 & 7037 & 5122 & 3153 & 3844 \\
\hline & $\mathrm{C}$ & 2304 & 2340 & 2727 & 3570 & 4245 & 4070 & 2730 \\
\hline \multirow{3}{*}{$\begin{array}{l}\mathrm{U}_{\mathrm{x}, \max } \\
{[\mathrm{cm}]}\end{array}$} & A & 2.56 & 2.34 & 2.65 & 2.80 & 4.11 & 3.34 & 1.96 \\
\hline & B & 6.78 & 5.76 & 23.64 & 13.20 & 8.78 & 4.80 & 5.68 \\
\hline & C & 2.81 & 2.83 & 5.53 & 6.66 & 7.10 & 6.21 & 3.74 \\
\hline \multirow{3}{*}{$\begin{array}{l}\mathrm{U}_{\mathrm{d}, \max } \\
{[\mathrm{cm}]}\end{array}$} & A & - & 5.63 & 2.08 & 3.85 & 7.14 & 9.62 & 10.98 \\
\hline & $\mathrm{B}$ & - & 18.65 & 11.22 & 18.25 & 31.45 & 41.25 & 46.35 \\
\hline & $\mathrm{C}$ & - & 8.11 & 4.00 & 8.55 & 17.20 & 20.66 & 18.34 \\
\hline \multirow{3}{*}{$\begin{array}{l}\mathrm{F}_{\mathrm{c}, \max } \\
{[\mathrm{kN}]}\end{array}$} & $\mathrm{A}$ & - & 190.37 & 78.44 & 149.67 & 374.18 & 429.37 & 323.80 \\
\hline & B & - & 244.94 & 689.11 & 707.58 & 761.08 & 631.34 & 1094.89 \\
\hline & $\mathrm{C}$ & - & 173.43 & 163.03 & 362.28 & 636.76 & 822.60 & 663.67 \\
\hline
\end{tabular}


The performance index for structural safety of the system is defined as the Effective Energy Deformation Index, EEDI that physically represents the amount of input seismic energy dissipated by the hysteretic device for the entire seismic input time duration. An increase of the cable diameter is associated with a respective increase of the earthquake energy dissipation achieved by ADCS2$\mathrm{C}_{\mathrm{d}}$. This is registered in all three seismic cases. The respective EEDI values range from 26 to $98 \%$ in case A, from 12 to $92 \%$ in case B and from 44 to $86 \%$ in case C. ADCS2- $\mathrm{C}_{\mathrm{d}}$ dissipate on average $73 \%$ of the earthquake input energy in case $\mathrm{A}, 59.4 \%$ in case $\mathrm{B}$ and $68.8 \%$ in case $\mathrm{C}$. Compared to the maximum EEDI values obtained in the current study, $\mathrm{ADCS} 2-\mathrm{C}_{\mathrm{Fd}}$ developed slightly lower values, by 12 and $11 \%$ in case $\mathrm{A}$ and $\mathrm{B}$ respectively. The dissipated energy by both systems in case $\mathrm{C}$ is practically equal.

A possible increase in the energy input back to the seismic control system, attributed to an increase of the base shear of the controlled system, may lead to damage under repeated excitation cycles. Minimum values of ADCS2- $C_{d}$ maximum base shear responses are registered with minimum cable diameter in seismic case A and $\mathrm{C}$. In case B the minimum respective value is obtained with $30 \mathrm{~mm}$ cable diameter. The maximum respective response values are obtained with $25 \mathrm{~mm}$ cable diameter in case $A$ and $C$ and with $15 \mathrm{~mm}$ cable diameter in case $B$. The maximum base shear response of ADCS2- $\mathrm{C}_{\mathrm{d}}$ amounts on average to $1754.6,6160.8$ and $3468.4 \mathrm{kN}$ in the three seismic cases respectively. Compared to the minimum base shear responses obtained in the current study, $\mathrm{ADCS} 2-\mathrm{C}_{\mathrm{Fd}}$ developed by 32 and $35 \%$ higher values in case $\mathrm{A}$ and $\mathrm{B}$ respectively, whereas a reduced value of $14 \%$ is developed in case $\mathrm{C}$. Compared to the primary frame, the respective maximum response reduction by ADCS2$\mathrm{C}_{\mathrm{d}}$ amounts to 38 and $43 \%$ in case $\mathrm{A}$ and $\mathrm{B}$ respectively. An increase by $16 \%$ of the maximum response is registered in case $\mathrm{C}$.

In compliance to the maximum base shear results obtained, minimum values of the systems maximum relative displacements are registered with maximum cable diameter in seismic case $\mathrm{A}$ and $\mathrm{C}$. In case $\mathrm{B}$ the minimum respective value is obtained again with $30 \mathrm{~mm}$ cable diameter. The maximum respective response values are obtained with $25 \mathrm{~mm}$ cable diameter in case A and C and with $15 \mathrm{~mm}$ cable diameter in case B. The maximum relative displacements of ADCS2- $C_{d}$ amount on average to $2.97,11.22$ and $5.85 \mathrm{~cm}$ in the three seismic cases respectively. Compared to the minimum respective responses obtained in the current study, ADCS2- $\mathrm{C}_{\mathrm{Fd}}$ developed by 16 and $17 \%$ higher values in case $\mathrm{A}$ and $B$ respectively, whereas a reduced value of $24 \%$ is developed in case C. Compared to the primary frame, the respective maximum response reduction by ADCS2 $-C_{d}$ amounts to 23 and $29 \%$ in case A and B respectively. An increase of the maximum response of $25 \%$ is registered in case $C$.

The hysteretic dampers deformations due to shear action reach maximum values through relative displacements of the primary system to the bracing member attached. The chevron bracing induces further increase of the dampers shear deformations through its re-centering action. Maximum shear deformations of the integrated damper are developed with maximum cable diameter in seismic 
case $A$ and $B$. In case $C$ the maximum respective value is developed with $30 \mathrm{~mm}$ cable diameter. The minimum respective response values are obtained with smallest cable diameter in all cases. The maximum base shear response of ADCS2- $\mathrm{C}_{\mathrm{d}}$ amounts on average to $1754.6,6160.8$ and $3468.4 \mathrm{kN}$ in the three seismic cases respectively. Compared to the maximum dampers shear deformations obtained in the current study, ADCS2- $\mathrm{C}_{\mathrm{Fd}}$ developed by 49,60 and $61 \%$ lower values in the three cases respectively.

Minimum tension forces in the cable members are developed with smallest cable diameter in case $\mathrm{A}$ and $\mathrm{C}$ and with $30 \mathrm{~mm}$ cable diameter in case $\mathrm{B}$. The maximum respective response values are obtained with $30 \mathrm{~mm}$ cable diameter in seismic case $\mathrm{A}$ and $\mathrm{C}$ and maximum cable diameter in case $\mathrm{B}$. In all ADCS2- $\mathrm{C}_{\mathrm{d}}$ the maximum cable forces resulting from the combined prestress and the individual seismic cases are kept under the respective elastic limit strength of the tension-only members material that amounts to $\mathrm{f}_{\mathrm{e}}=140 \mathrm{kN} / \mathrm{cm}^{2}$ and corresponds to $1346.96 \mathrm{kN}$ for a diameter $\mathrm{C}_{\mathrm{d}}=35 \mathrm{~mm}, 989.60 \mathrm{kN}$ for $\mathrm{C}_{\mathrm{d}}=30 \mathrm{~mm}, 687.22$ $\mathrm{kN}$ for $\mathrm{C}_{\mathrm{d}}=25 \mathrm{~mm}, 439.82 \mathrm{kN}$ for $\mathrm{C}_{\mathrm{d}}=20 \mathrm{~mm}$ and $247.40 \mathrm{kN}$ for $\mathrm{C}_{\mathrm{d}}=15 \mathrm{~mm}$. The maximum tension forces in the cable members of ADCS2 $-\mathrm{C}_{\mathrm{d}}$ amounts on average to $271.09,776.80$ and $529.67 \mathrm{kN}$ in the three seismic cases respectively. Compared to the minimum cable forces obtained in the current study, ADCS2$\mathrm{C}_{\mathrm{Fd}}$ developed by 59 and $5 \%$ higher axial forces in case $\mathrm{A}$ and $\mathrm{C}$ respectively, whereas a reduced value of $61 \%$ is obtained in case B.

Based on the numerical analysis results, $A D C S 2-C_{d}$ with $30 \mathrm{~mm}$ cable diameter, ADCS2 $-\mathrm{C}_{\mathrm{d}}=30$, is selected, in order to achieve highest possible energy dissipation and prevent substantial increase of the base shear and relative displacements of the controlled system. The earthquake time history responses of the selected controlled system are presented in the following sections.

\subsection{Energy dissipation}

The energy dissipation time history by ADCS2 $-\mathrm{C}_{\mathrm{d}}=30$ and the respective forcedeformation behaviour in the three seismic cases considered in the analysis are shown in fig. 2. In all cases the accumulated energy dissipation rate reaches its maximum in the first $25 \mathrm{~s}$ of the earthquake loadings. The derived hysteresis loops indicate a rigid-plastic behaviour by the hysteretic damper.

\subsection{Base shear}

The base shear time history of the primary frame and ADCS2- $C_{d}=30$ in the three seismic cases is shown for the first $15 \mathrm{~s}$ of the excitations in fig. 3 . Compared to the primary frame the maximum base shear of the controlled system is slightly increased by $4 \%$ in seismic case A and $43 \%$ in case $\mathrm{C}$. The respective maximum value is decreased by $35 \%$ in case $B$. 

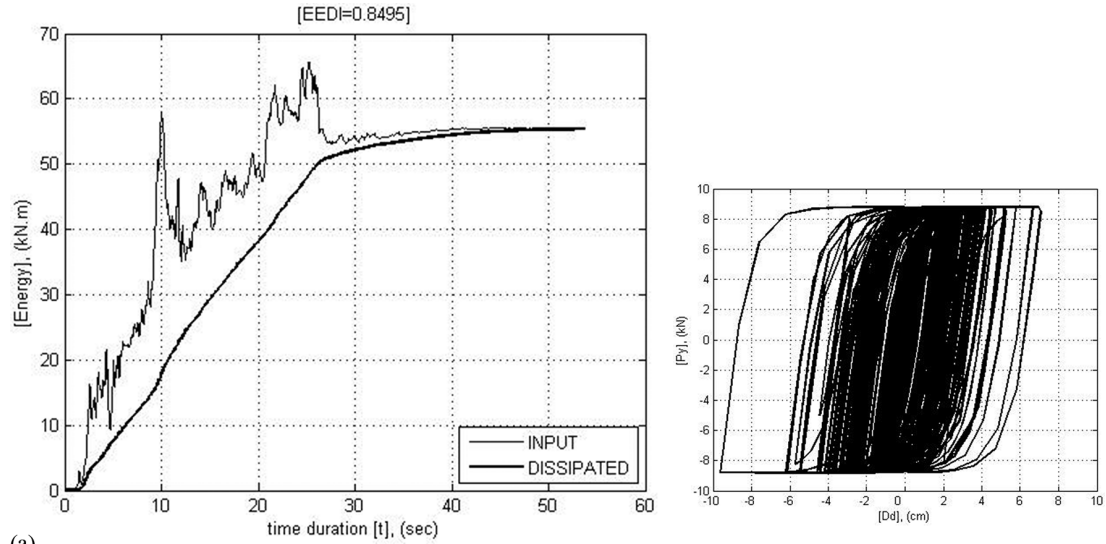

(a)
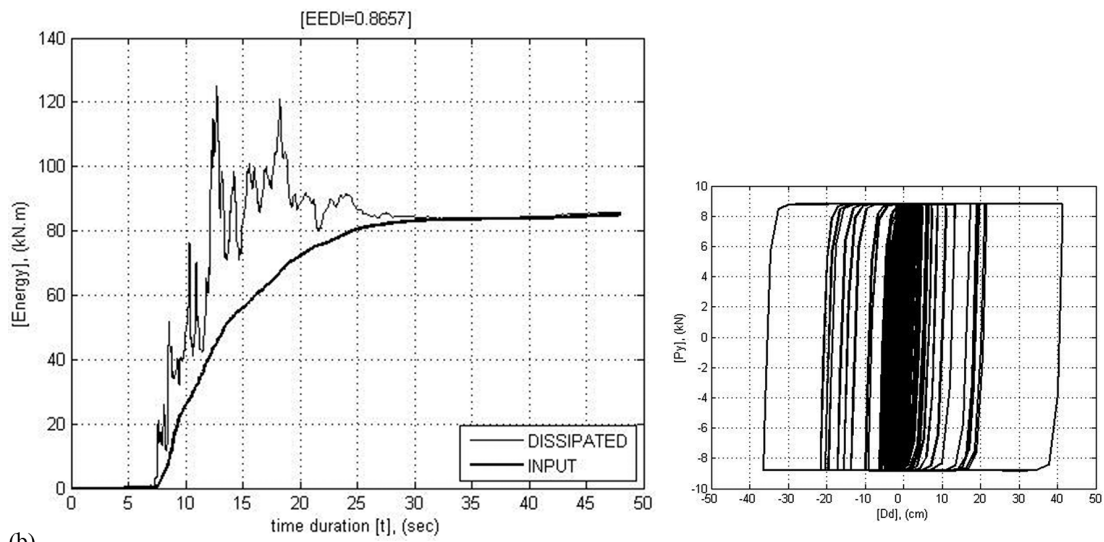

(b)
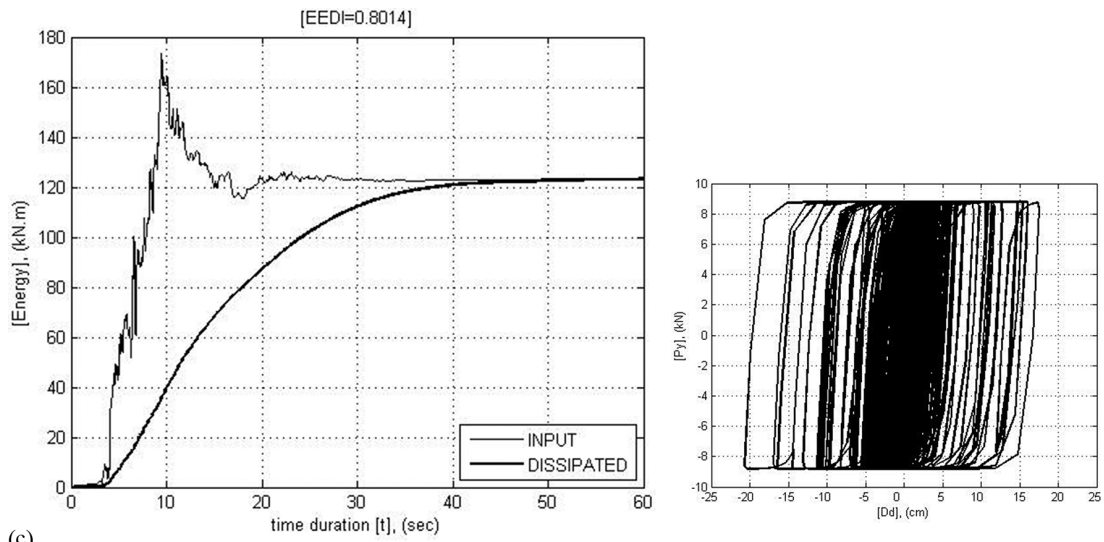

Figure 2: $\quad$ ADCS2- $\mathrm{C}_{\mathrm{d}}=30$ - hysteretic energy dissipation- and forcedeformation behaviour: (a) Seismic case A; (b) Seismic case B; (c) Seismic case C. 

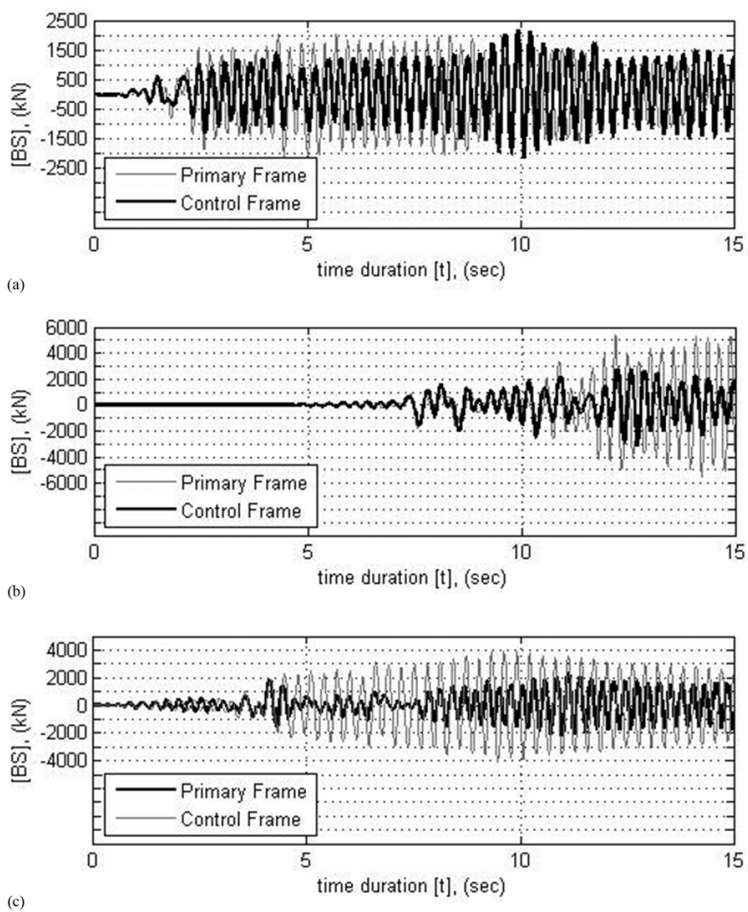

Figure 3: $\quad$ Primary and ADCS2 $-\mathrm{C}_{\mathrm{d}}=30$ - controlled systems base shear BS time history: (a) Seismic case A; (b) Seismic case B; (c) Seismic case C.

\subsection{Relative displacements}

The relative displacements time history of the primary frame and ADCS2 $-\mathrm{C}_{d}=$ 30 in the three seismic cases are shown for the first $15 \mathrm{~s}$ of the excitations in fig. 4. Compared to the primary frame the maximum relative displacements of the controlled system are increased by 23 and $55 \%$ in seismic case A and C respectively, whereas the respective maximum value is decreased by $29 \%$ in case B.

\subsection{Dampers shear deformations}

The dampers shear deformations time history of ADCS2- $\mathrm{C}_{\mathrm{d}}=30$ are compared with the controlled systems relative displacements in the three seismic cases for the first $15 \mathrm{~s}$ of the excitations as shown in fig. 5. Compared to the maximum relative displacements of the controlled system the respective dampers shear deformations are increased by 65,88 and $70 \%$ in the three seismic cases respectively. 

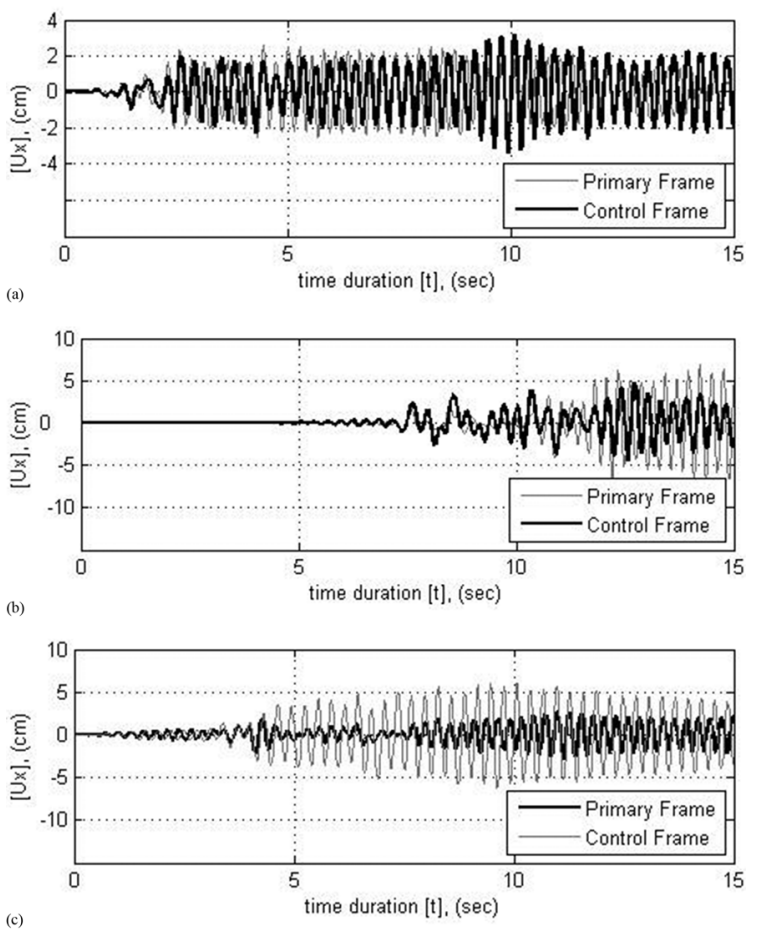

Figure 4: Primary and $\mathrm{ADCS} 2-\mathrm{C}_{\mathrm{d}}=30-$ controlled systems relative displacements $U_{x}$ - time history: (a) Seismic case A; (b) Seismic case B; (c) Seismic case C.

\section{Conclusions}

In the current paper a bracing configuration of an Adaptable Dual Control System is analytically investigated in its nonlinear dynamic responses under international strong earthquake ground motions. The control mechanism consists of a portal- and a chevron cable bracing of closed circuit and a hysteretic damper of triangular-shaped steel plates. The damper has proven to be able to dissipate satisfactory portions of the earthquake input energy, while the primary frame and the bracing members develop an exclusive elastic behaviour. Following previous related studies conducted by the authors, in the present study the controlled system has been investigated in its dynamic responses, by modelling the bracing members as cable elements, while including both, tension-stiffening and large deflections nonlinearity in the members' response. The dynamic analyses conducted, based on a constant pretension stress of the cables, revealed certain differences in the nonlinear earthquake system responses according to the cables 

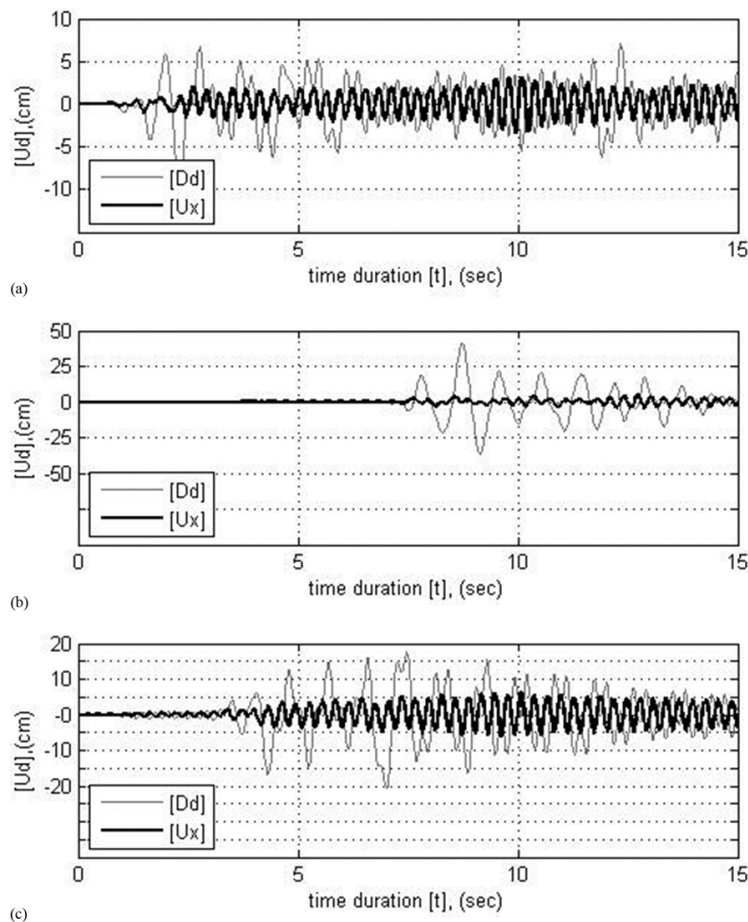

Figure 5: $\quad A D C S 2-C_{d}=30-$ dampers shear deformations $U_{d}$ and ADCS2$\mathrm{C}_{\mathrm{d}}=30-$ controlled systems relative displacements $\mathrm{U}_{\mathrm{x}}-$ time history: (a) Seismic case A; (b) Seismic case B; (c) Seismic case C.

stiffness of the control system. A selected higher cable diameter for the bracing members than the one proposed in previous studies provided respectively further slight improvements in the earthquake response of the controlled system.

\section{References}

[1] Towashiraporn, P., Park, J., Goodno, B.J. \& Craig, J.I., Passive Control Methods for Seismic Response Modification. Progress in Structural Engineering and Materials, 4, pp. 74-86, 2002.

[2] Di Sarno, L. \& Elnashai, A.S., Innovative Strategies for Seismic Retrofitting of Steel and Composite Structures. Progress in Structural Engineering and Materials, 7, pp. 115-135, 2005.

[3] Martelli, A., Seismic Isolation and Energy Dissipation: Worldwide Application and Perspectives. Earthquake Resistant Engineering Structures VI, ed. Brebbia, C.A., WIT Press: Southampton, pp. 105-116, 2007.

[4] Inoue, K. \& Kuwahara, S., Optimum Strength Ratio of Hysteretic Damper. Earthquake Engineering and Structural Dynamics, 27, pp. 577-588, 1998. 
[5] Mayes, R., Goings, C., Naguib, W., Harris, S., Lovejoi, J., Fanucci, J., Bystricky, P. \& Hayes J., Comparative Performance of BucklingRestrained Braces and Moment Frames. Proceedings of 13th World Conference on Earthquake Engineering: Vancouver, Canada, Paper No. 2287, 2004.

[6] Filiautrault, A. \& Cherry, S., Comparative Performance of Friction Damped Systems and Base Isolation Systems for Earthquake Retrofit and Aseismic Design. Earthquake Engineering and Structural Dynamics, 16, pp. 389416, 1988.

[7] Renzi, E., Perno, S., Pantanella, S. \& Ciampi, V., Design, Test and Analysis of a Light-Weight Dissipative Bracing System for Seismic Protection of Structures. Earthquake Engineering and Structural Dynamics, 36, pp. 519-539, 2007.

[8] Kurata, M., DesRoches, R. \& Leon, R.T., Cable Damper Bracing for Partial Seismic Rehabilitation. 14th World Conference on Earthquake Engineering, 14WCEE, 12.10-17.10.08: Beijing, China, October 2008.

[9] Phocas, M.C. \& Pocanschi, A., Steel Frames with Bracing Mechanism and Hysteretic Dampers. Earthquake Engineering and Structural Dynamics, 32, pp. 811-825, 2003.

[10] Sophocleous, T. \& Phocas, M.C., Dual Earthquake Resistant Frames. Earthquake Resistant Engineering Structures VII, eds. Phocas, M., Brebbia, C.A., Komodromos, P., WIT Press: Southampton, pp. 165-174, 2009.

[11] Xia, C. \& Hanson, R.D., Influence of ADAS Element Parameters on Building Seismic Response. Structural Engineering, 118(7), pp. 19031918, 1992.

[12] Aiken, I.D., Nims, D.K., Whittaker, A.S. \& Kelly, J.M., Testing of Passive Energy Dissipation Systems. Earthquake Spectra, 9(3), pp. 335-369, 1993.

[13] Tsai, K.C., Chen, H.W., Hong, C.P. \& Su, Y.F., Design of Steel Triangular Plate Energy Absorbers for Seismic-Resistance Construction. Earthquake spectra, 9, pp. 505-528, 1993.

[14] Phocas, M.C. \& Sophocleous, T., Adaptable Dual Control Systems. A Comparative Parametric Analysis. Safety and Security Engineering, 2(3), pp. 280-296, 2012. 